\title{
Plantas relatadas como tóxicas para ruminantes no semiárido nordestino
}

\author{
Plants reported as toxic to ruminants in the Brazilian northeastern semiarid region \\ José Jailson Lima Bezerra ${ }^{1} \&$ Vivyanne Santos Falcão-Silva ${ }^{\star}$ \\ ${ }^{1}$ Universidade Federal de Pernambuco, Recife, PE, Brasil. \\ ²Universidade Federal da Paraíba, João Pessoa, PB, Brasil.* Autor para correspondência: vivyannefalcao@yahoo.com.br.
}

Submissão: 10/09/2017 / Aceite: 25/02/2019

\begin{abstract}
RESUMO
Ao longo dos anos as intoxicações por plantas têm causado prejuízos significativos para os criadores de ruminantes de várias regiões do Brasil, afetando de forma direta o setor pecuário do país. Desta forma, objetivou-se realizar um levantamento com produtores, médicos veterinários, zootecnistas, engenheiros agrônomos e técnicos agrícolas sobre as principais plantas que causam intoxicações em ruminantes no Curimataú Paraibano. O presente trabalho foi realizado em cinco municípios da microrregião do Curimataú Ocidental Paraibano, incluindo Barra de Santa Rosa, Cuité, Damião, Nova Floresta e Sossego. As entrevistas foram realizadas por meio de três formulários estruturados, contendo indagações específicas sobre casos de intoxicações identificados na referida microrregião. Para a realização desta pesquisa, foram entrevistados 30 participantes (6 representantes de cada município) entre os meses de junho e outubro de 2016. A partir dos dados obtidos por meio das entrevistas, verificou-se que as principais plantas comprovadamente tóxicas do Curimataú Ocidental Paraibano, segundo os entrevistados, foram: Anadenanthera colubrina, Mascagnia rigida, Prosopis juliflora e Manihot glaziovii. Muitos entrevistados demonstram não conhecer o princípio tóxico de outras plantas presentes na região e citadas na literatura como responsáveis por intoxicações em ruminantes, tais como: Mimosa tenuiflora, Crotalaria retusa e a Solanum paniculatum. As plantas Physalis angulata e Ricinus communis foram mencionadas como tóxicas, mas estudos toxicológicos devem ser realizados para comprovar a toxicidade das mesmas. Tais resultados demonstram que são necessárias medidas profiláticas eficazes nas propriedades rurais, evitando, assim, a ocorrência de surtos e mortes de ruminantes.
\end{abstract}

PALAVRAS-CHAVE: animais de produção, intoxicações por plantas, semiárido brasileiro.

\section{ABSTRACT}

Over the years the plant poisonings have caused significant losses to ruminant producers from various Brazilian regions, affecting the livestock sector in the country. Thus, this study aims to conduct a survey with producers, veterinarians, zootechnists, agronomists and agricultural technicians about the major plants poisoning ruminants in the Curimataú Paraibano. This study was conducted in five cities in the Curimataú Ocidental Paraibano, including Barra de Santa Rosa, Cuité, Damião, Nova Floresta and Sossego. The interviews were conducted through three structured forms, containing specific questions about poisoning cases identified in the microregion cited. To carry out this survey, a total of 30 participants were interviewed (six representatives from each city) between June and October 2016. From the data obtained from the interviews, one found the main toxic plants in Curimataú Ocidental Paraibano, from the viewpoint of those interviewed, were: Anadenanthera colubrina, Mascagnia rigida, Prosopis juliflora, and Manihot glaziovii. Many interviewees demonstrate they don't know the toxic principle of other plants present in the region and cited in the literature as responsible for poisoning in ruminants, such as: Mimosa tenuiflora, Crotalaria retusa and Solanum paniculatum. The plants Physalis angulata and Ricinus communis were mentioned as toxic, but new experiments must be carried out to prove their toxicity. These results show effective prophylactic measures are necessary in rural properties, thus preventing the occurrence of outbreaks and deaths of ruminants.

KEYWORDS: production animals, plant poisoning, Brazilian semiarid region. 


\section{INTRODUÇÃO}

As intoxicações por plantas em ruminantes vêm sendo estudadas e comprovadas cientificamente ao longo dos anos. Na pecuária brasileira, assim como na de muitos outros países, uma expressiva causa de prejuízos é a ingestão de plantas tóxicas por animais de produção (BARBOSA et al. 2007). Segundo RIETCORREA et al. (2012), este problema não é recente, pois as intoxicações por plantas em animais de produção são conhecidas no país desde a introdução dos primeiros bovinos pelos pioneiros portugueses em pastagens naturais brasileiras. MAGALHÃES et al. (2013) dizem que o interesse pelo estudo das plantas tóxicas cresce a cada dia no Brasil e no mundo, visto que as plantas são a base da alimentação dos ruminantes e estes na sua maioria são criados de forma extensiva.

$\mathrm{Na}$ região semiárida nordestina, por exemplo, é comum que animais sejam intoxicados por plantas durante os períodos de estiagem, onde muitas plantas tóxicas permanecem verdes e atrativas (SILVA et al. 2008). Para CARVALHO et al. (2009), o princípio ativo de muitas espécies de plantas tóxicas descritas no Brasil são desconhecidos, e esse conhecimento é necessário para desenvolver técnicas mais eficientes de controle das intoxicações, pois sabe-se que o consumo destas plantas por animais de produção pode leválos a morte e, consequentemente, causar prejuízos significativos para a pecuária brasileira.

Com base nas investigações de ASSIS et al. (2010), estima-se que as intoxicações por plantas no Estado da Paraíba em ruminantes e equinos representam uma perda econômica anual, por morte de animais, de $R \$ 2.733 .097,00$, o que justifica plenamente investir na divulgação de medidas preventivas, além da realização de pesquisas para melhor conhecimento das intoxicações e determinação das formas mais adequadas de controle e profilaxia (PESSOA et al. 2013).

Desta forma, sabendo-se dos altos índices de intoxicações por plantas em animais de produção na Paraíba, objetivou-se realizar um levantamento das principais espécies de plantas tóxicas, tomando-se como base os relatos feitos por produtores, médicos veterinários, engenheiros agrícolas, técnicos agrícolas e zootecnistas que exercem suas atividades nas zonas rurais do Curimataú Ocidental Paraibano.

\section{MATERIAL E MÉTODOS}

Este trabalho foi realizado a partir da coleta de dados por meio de entrevistas realizadas com criadores de ruminantes e profissionais em cinco municípios da microrregião do Curimataú Ocidental Paraibano, entre os meses de junho e outubro de 2016.

\section{Descrição da área de estudo}

A microrregião do Curimataú Ocidental localiza-se no Estado da Paraíba e pertence à mesorregião do Agreste Paraibano (Figura 1). Segundo o IBGE sua população é de 117.369 habitantes (IBGE 2010), e está dividida em 11 municípios distribuídos numa área total de $3.962 \mathrm{~km}^{2}$ (FIEP/SEBRAE 2010). Ainda segundo o IBGE, no estado da Paraíba há um rebanho de 1.354 .457 bovinos, 442.589 ovinos, 461.401 caprinos e 47.077 equinos (IBGE 2006). O sistema associativo, com a produção desses ruminantes, se caracterizou como esquema mais utilizado pelos produtores da Paraíba (COSTA et al. 2007).

\section{Procedimentos para realizar a pesquisa}

Para determinar a ocorrência das intoxicações por plantas na microrregião do Curimataú Ocidental da Paraíba, entrevistou-se um número de 30 participantes no total, incluindo produtores rurais $(n=25)$, engenheiros agrônomos $(n=2)$, médico veterinário $(n=1)$, zootecnista $(n=1)$ e técnico agropecuário $(n=$ 1), que estão envolvidos com a criação de ruminantes em cinco municípios desta microrregião (Barra de Santa Rosa, Cuité, Damião, Nova Floresta e Sossego).

A metodologia baseia-se na descrita por SILVA et al. (2006). Neste sentido, para a realização das entrevistas foram utilizados três formulários. Os formulários 1 e 2 foram aplicados a todos os entrevistados e o formulário 3 somente àqueles que se mostraram interessados em descrever surtos de intoxicações que presenciaram.

- Formulário 1: Consta o nome científico e popular de 15 plantas tóxicas descritas na região Nordeste, com ênfase no estado da Paraíba. Perguntou-se sobre a existência de cada planta na região e os possíveis casos de intoxicação que o entrevistado presenciou. No momento das entrevistas, fotos das plantas foram apresentadas ao entrevistado.

- Formulário 2: Questionou-se sobre a ocorrência de outras plantas conhecidas como tóxicas pelos entrevistados e que não foram incluídas no formulário 1, e os efeitos clínicos causados pelas mesmas.

- Formulário 3: Os entrevistados relataram sobre as características das intoxicações observadas.

\section{Análise dos resultados}

As informações obtidas por meio dos formulários aplicados sob a forma de entrevistas foram analisadas quanti-qualitativamente. Os dados quantitativos obtidos através do formulário 1 foram agrupados 
em uma tabela por meio de valores percentuais de frequência relativa (FR) sobre as informações dos entrevistados acerca do conhecimento das plantas, e se eles já haviam presenciado intoxicações em ruminantes causadas pela ingestão destes vegetais tóxicos. A FR foi calculada tomando-se como base a fórmula de AMOROZO \& GÉLY (1988) com adaptações:

Frequência relativa dos entrevistados que conheciam a planta ( $\left.F R_{C P}\right)$

$F R_{C P}=$ Número total de informações que conheciam as plantas $\left(N T I_{C P}\right)$ x 100/ Número de citações da planta $(\mathrm{N})$

Frequência relativa dos relatos de intoxicações $\left(F R_{R I}\right)$

$F R_{R I}=$ Número total de informações que relataram intoxicações $\left(N T I_{R I}\right) \times 100 /$ Número de citações de intoxicação da planta $\left(\mathrm{N}_{\mathrm{I}}\right)$

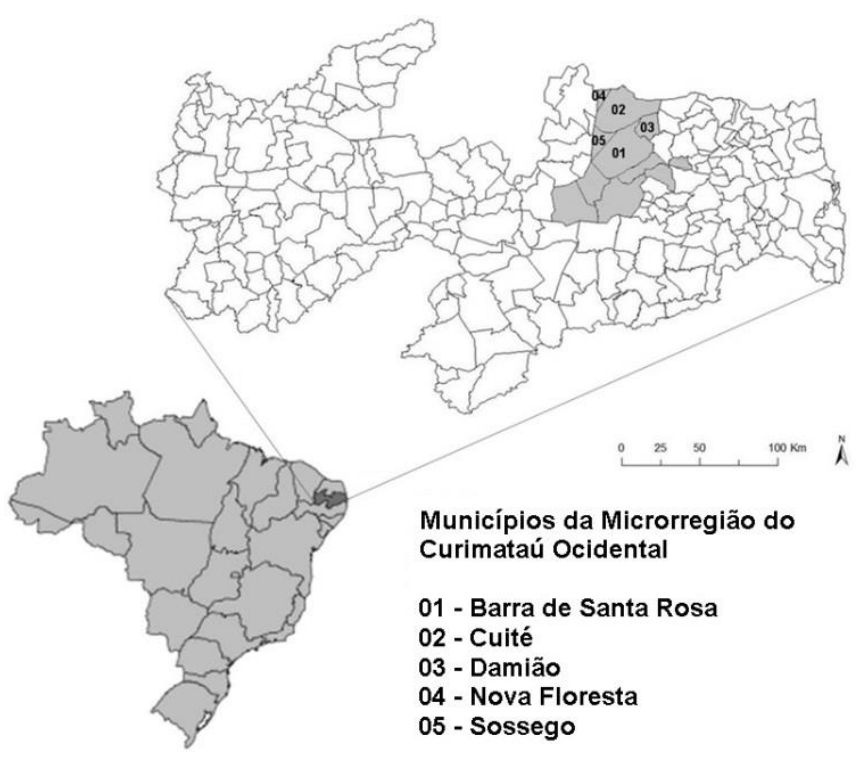

Figura 1. Mapa geográfico do Brasil destacando o Estado da Paraíba em maior aumento, com ênfase nos municípios da microrregião do Curimataú Ocidental.(Fonte: http://www.coisaspraver.com/2013/02/ mapa-da-paraiba-com-todos-os-municipios.html - Adaptado).

Figure 1. Geographic map of Brazil highlighting the state of Paraíba in greater increase, with emphasis on the cities of the microregion of Curimataú Ocidental. (Source: http://www.coisaspraver.com/2013/02/ mapa-da-paraiba-com-todos-os-municipios.html - Adapted).

Os relatos obtidos através dos formulários 2 e 3 foram representados de forma descritiva, levando em consideração as observações dos participantes desta pesquisa.

Procedimentos éticos

O Comitê de Ética em Pesquisa do Hospital Universitário Alcides Carneiro da Universidade Federal de Campina Grande (HUAC - UFCG) aprovou a presente pesquisa sob o processo 056783/2016.

\section{RESULTADOS E DISCUSSÃO}

Alguns exemplares de plantas tóxicas presentes no formulário 1 e relatadas como tóxicas para os ruminantes durante a realização das entrevistas estão representadas na Tabela 1, onde pode-se observar 0 nome científico e popular das espécies, o número de participantes que identificaram a planta em suas propriedades e a quantidade de entrevistados que presenciaram as intoxicações pelas plantas em animais de produção.

\section{Descrição das intoxicações por plantas conhecidas como tóxicas no Estado da Paraíba (formulários 1 e 3). \\ Anadenanthera colubrina (Vell.) Brenan ("Angico")}

Os relatos sobre as intoxicações causadas pelo "Angico" foram expressivos, tendo em vista que todos os entrevistados identificaram essa planta em suas propriedades, e destes, 32,87\% $\left(\mathrm{N}_{\mathrm{I}}=24\right)$ relataram ter presenciado animais desenvolvendo sinais clínicos depois que ingeriram folhas murchas da planta após serem podadas. Segundo os produtores, esta é a principal forma observada de intoxicação por $A$. colubrina.

Um produtor de ruminantes do município de Cuité relatou que em 2015 um bovino foi intoxicado pelas folhas de "Angico". O animal se recuperou após tratamento empírico administrando-se por via oral uma suspensão composta por "feijão-bravo" (Capparis flexuosa L.) e alho. Tendo em vista este fato isolado 
observado pelo produtor, não se pode afirmar com certeza se esta espécie de "garrafada" realmente possui atividade terapêutica capaz de curar a intoxicação ocasionada pelo "Angico". Existem dados na literatura que comprovam os efeitos de $C$. flexuosa na cura de doenças venéreas e para dor de dente em humanos (ARAÚJO 2009), porém é desconhecido seu uso para o tratamento de intoxicações em animais.

Tabela 1. Plantas conhecidas como tóxicas no Estado da Paraíba (formulário 1), sob o ponto de vista dos entrevistados na microrregião do Curimataú Ocidental Paraibano, 2016.

Table 1. Plants known as toxic in the state of Paraíba (Form I), from the viewpoint of the interviewees in the microregion of Curimataú Ocidental Paraibano, 2016.

\begin{tabular}{|c|c|c|c|c|c|}
\hline \multirow[t]{2}{*}{ Nome científico } & \multirow[t]{2}{*}{ Nome popular } & \multicolumn{2}{|c|}{ Conheciam a planta } & \multicolumn{2}{|c|}{$\begin{array}{l}\text { Relataram } \\
\text { intoxicações }\end{array}$} \\
\hline & & $\overline{\mathrm{N}}$ & $\mathrm{FR}_{\mathrm{CP}}(\%)$ & $\mathrm{N}_{\mathrm{I}}$ & $\mathrm{FRRI}_{\mathrm{RI}}(\%)$ \\
\hline $\begin{array}{l}\text { Anadenanthera colubrina (Vell.) } \\
\text { Brenan }\end{array}$ & Angico & 30 & 13,82 & 24 & 32,87 \\
\hline Brachiaria decumbens Stapf & Capim braquiária & 25 & 11,52 & 7 & 9,59 \\
\hline Crotalaria retusa L. & Chocalho-de-cobra & 17 & 7,83 & 3 & 4,11 \\
\hline $\begin{array}{l}\text { Enterolobium contortisiliquum (Vell.) } \\
\text { Morong }\end{array}$ & Tambor & 20 & 9,22 & 2 & 2,74 \\
\hline $\begin{array}{l}\text { Ipomoea asarifolia (Desr.) Roem. \& } \\
\text { Schult. }\end{array}$ & Salsa & 9 & 4,15 & 1 & 1,37 \\
\hline Lantana camara L. & Chumbinho & 7 & 3,23 & 1 & 1,37 \\
\hline Mascagnia rigida (A.Juss.) Griseb. & Tingui & 20 & 9,22 & 14 & 19,18 \\
\hline Mimosa tenuiflora (Willd.) Poir. & Jurema-preta & 30 & 13,82 & 3 & 4,11 \\
\hline Palicourea marcgravii A.St.-Hil. & Erva-de-rato & 4 & 1,84 & 3 & 4,11 \\
\hline Prosopis juliflora (Sw.) DC. & Algaroba & 30 & 13,82 & 12 & 16,44 \\
\hline Solanum paniculatum $\mathrm{L}$. & Jurubeba & 25 & 11,53 & 3 & 4,11 \\
\hline$\overline{\text { Total }}$ & & 217 & 100,00 & 73 & 100,00 \\
\hline
\end{tabular}

$\overline{\mathrm{FRCP}}=$ Frequência relativa dos entrevistados que conheciam as plantas; $\mathrm{N}=$ Número de citações da planta; $\mathrm{FRR}_{\mathrm{RI}}=$ Frequência relativa dos relatos de intoxicações; $N_{I}=$ Número de citações intoxicação da planta.

O entrevistado relatou, ainda, que após identificar a intoxicação por $A$. colubrina no bovino, não houve modificação no manejo dos animais que eram criados para o abate. A intoxicação ocorreu em um período de estiagem, quando os bovinos se encontravam soltos no pasto. Dentre os principais sinais clínicos apresentados pelos animais intoxicados, destacam-se dificuldades para se alimentar e ingerir água, timpanismo e pelos arrepiados.

Segundo SILVA et al. (2006), a intoxicação por A. colubrina acontece quando galhos destas árvores são cortados e ficam acessíveis aos animais no pasto, portanto, faz-se necessária a retirada dos animais nos locais com a presença destas plantas, ou que após a poda, todos os galhos e folhas sejam queimados ou removidos. Ainda segundo estes autores, os sinais clínicos caracterizaram-se por dificuldade para movimentar-se, timpanismo, ataxia, pelo arrepiado, dificuldade respiratória e quedas, havendo uma grande probabilidade de morte dos animais com esse quadro de intoxicação. Além destes sintomas, TOKARNIA et al. (1999c) observaram que bovinos intoxicados por $A$. colubrina apresentavam leves tremores musculares, taquicardia e leve apatia.

Brachiaria decumbens Stapf (“Capim braquiária”)

Dentre os entrevistados, $11,52 \%(N=25)$ relataram ter conhecimento sobre a presença de $B$. decumbens em suas propriedades, mas devido ao longo período de estiagem, a forragem encontrava-se quase que escassa nas regiões onde se realizou esta pesquisa. Um produtor do município de Damião mencionou que presenciou um caso de intoxicação por "Capim braquiária". Um médico veterinário de Nova Floresta relatou que em 2015 atendeu dois casos de bovinos intoxicados por B. decumbens. Segundo o veterinário, os animais apresentavam um quadro clínico de fotossensibilização.

Alguns pesquisadores identificaram que os principais sinais clínicos causados pela intoxicação por Brachiaria spp. em bovinos são caracterizados por fotossensibilização e progressiva perda de peso, evoluindo posteriormente para casos de anorexia, além destes sintomas, os animais apresentaram também dermatite com pele espessada e formação de crostas e icterícia (SOUZA et al. 2010, RIET-CORREA et al. 2011). 
Crotalaria retusa L. ("Guizo de cascavel")

Intoxicações causadas por $C$. retusa foram identificadas por produtores dos municípios de Barra de Santa Rosa, Cuité e Nova Floresta. Os entrevistados relataram que os animais apresentaram emagrecimento acentuado ao longo do tempo e que os animais mais susceptíveis eram os bovinos.

Para SANTOS et al. (2008), os animais mais susceptíveis às intoxicações por $C$. retusa são de fato os bovinos e equinos, devido à presença de alcalóides pirrolizidínicos, que causam fibrose hepática (LUCENA et al. 2010). Surtos de intoxicações também foram observados em ovinos introduzidos ocasionalmente em uma área severamente invadida por $C$. retusa em estágio de semeadura. Os principais sinais clínicos verificados nos animais intoxicados foram anorexia, depressão grave, icterícia leve, incoordenação e decúbito, além da morte de alguns indivíduos (NOBRE et al. 2005).

Enterolobium contortisiliquum (Vell.) Morong ("Tambor" ou "Timbó")

Casos de intoxicações em ruminantes associados à ingestão das favas do "Tambor" foram relatados por 2,74\% $\left(\mathrm{N}_{\mathrm{I}}=02\right)$ dos produtores. Os entrevistados afirmaram que os principais animais acometidos pelos princípios tóxicos de $E$. contortisiliquum são os bovinos, que têm uma maior facilidade para ingerir as favas dessa planta. Os animais intoxicados tendem a apresentar sinais clínicos como empanzinamento. Além de alterações no sistema digestório por intoxicação de $E$. contortisiliquum em bovinos, tem-se relatado fotossensibilização, lesões hepáticas e abortos (TOKARNIA et al. 1999b, MELLO et al. 2010, BEZERRA et al. 2012, OLINDA et al. 2015). Uma forma de tratamento para a intoxicação seria a retirada dos animais das áreas com a presença desta planta, bem como utilizar um protetor hepático para tratar as lesões mais graves dos indivíduos intoxicados (COSTA et al. 2009).

Ipomoea asarifolia (Desr.) Roem. \& Schult. ("Salsa")

A "Salsa" é frequentemente identificada no município de Barra de Santa Rosa, tendo em vista que $4,15 \%(N=09)$ dos participantes relataram a presença da planta em suas propriedades, inclusive, um produtor relatou que já presenciou vários casos de intoxicações em seu rebanho de caprinos e ovinos em decorrência dos efeitos tóxicos da planta. Percebeu-se que a maioria dos entrevistados dos outros municípios desconhece o potencial tóxico de $I$. asarifolia. Fato preocupante, visto que há diversos relatos de intoxicação por esta planta, estando os animais jovens mais susceptíveis do que os adultos (TORTELLI et al. 2008). Dentre os sinais clínicos descritos na literatura para a intoxicação por $l$. asarifolia, destacam-se: tremores musculares, ataxia, hipermetria acentuada, quedas, podendo levar ao óbito (BARBOSA et al. 2005, ARAÚJO et al. 2008, TORTELLI et al. 2008, OLIVEIRA et al. 2009).

Lantana camara L. ("Chumbinho")

Verificou-se que poucos produtores, $3,43 \%(\mathrm{~N}=07)$ conheciam a planta, isso se justifica pelo fato da L. camara ser típica de locais úmidos, desta forma ela torna-se escassa no Curimataú Paraibano por ser considerada uma região seca, mas pode ser identificada durante os períodos de precipitação. Apenas um produtor do município de Barra de Santa Rosa relatou ter visto casos de intoxicações pela planta, mas não forneceu outros detalhes.

Estudos realizados por TOKARNIA et al. (1999a) revelaram que surtos de intoxicação por "Chumbinho" em bovinos somente ocorrem em condições especiais, isto é, o gado só é intoxicado caso passe a ingerir a $L$. camara em grandes quantidades, o que é tipicamente observado em animais famintos ou que foram transferidos para uma área com grande quantidade desta planta. Registros de intoxicação por L. camara em ovinos também foram descritos por BRITO et al. (2004).

Mascagnia rigida (Juss.) Griseb. ("Tingui")

Essa planta é mencionada pelos produtores e pelos profissionais que exercem suas atividades nas zonas rurais dos municípios de Nova Floresta, Cuité e Barra de Santa Rosa, como sendo extremamente tóxica para ruminantes. Segundo os entrevistados dos municípios de Sossego e Damião, a planta não é encontrada nestas regiões, porém já ouviram relatos de casos de animais que tiveram morte súbita após terem ingerido a planta.

Um produtor do município de Nova Floresta relatou que no ano de 2015 dois bovinos foram intoxicados por $M$. rigida, os animais que eram criados para a produção de leite e para o abate e não conseguiram se recuperar e tiveram morte súbita. $O$ produtor relatou que caso os animais se alimentem do "Tingui" e permaneçam no local não desenvolvem sinais clínicos, mas, se os bovinos forem estimulados a praticarem exercício físico, apresentam tremores seguidos de morte. SILVA et al. (2008) explicam que este efeito provavelmente é causado por interferência no mecanismo energético, uma vez que o esforço físico promove aumento na necessidade energética do animal.

Além da morte súbita associada ao deslocamento dos animais que se alimentaram de $M$. rigida, PESSOA et al. (2015) verificaram que os caprinos intoxicados por esta planta apresentaram sinais clínicos 
como depressão, taquicardia, taquipneia, relutância ao movimento, mugidos, diarreia, incoordenação motora, tremores musculares e ingurgitamento da veia jugular com pulso venoso positivo.

Casos de intoxicações por $M$. rigida em ovinos e caprinos já foram relatados na Paraíba por VASCONCELOS et al. (2008), onde verificaram que os sinais clínicos apresentados por ovinos após a ingestão da planta eram caracterizados por tremores musculares, relutância em caminhar e queda. $\mathrm{E}$ quanto aos caprinos, os sinais se manifestavam quando os animais eram forçados a se exercitarem e consistiam em relutância em caminhar, queda e morte em 3 a 5 minutos após o início dos sinais.

Mimosa tenuiflora (Willd.) Poir. ("Jurema-preta")

Todos os entrevistados $(n=30)$ dos cinco municípios relataram que conheciam a Mimosa tenuiflora, porém apenas um médico veterinário de Nova Floresta e dois produtores de Barra de Santa Rosa mencionaram casos de intoxicações causadas pela ingestão das folhas da "Jurema-preta" por caprinos e ovinos prenhes. $O$ fato da planta $M$. tenuiflora ser amplamente conhecida na microrregião estudada está diretamente associada com a sua ocorrência em quase toda Região Nordeste, apresentando alto grau de resistência à seca e crescimento em solos rasos (ARAÚJO et al. 2004).

Segundo os entrevistados, a planta causa malformações congênitas durante o desenvolvimento embrionário em pequenos ruminantes. Sérios prejuízos causados pela $M$. tenuiflora foram relatados por um produtor do município de Barra de Santa Rosa, o mesmo contou que os surtos de intoxicações causadas por esta planta são muito frequentes e causam sérios problemas na reprodução de caprinos e ovinos. Só em 2016, o produtor identificou mais de 10 casos de ovelhas que pariram cordeiros com os membros atrofiados e lesões na boca, impedindo que os neonatos se alimentassem, o que causou a morte de todos os indivíduos.

Diversos estudos têm comprovado que Mimosa tenuiflora causa malformações congênitas em caprinos e ovinos. DANTAS et al. (2010) evidenciaram que ovelhas que se alimentaram de $M$. tenuiflora durante o período gestacional pariram cordeiros que apresentaram principalmente malformações mandibulares e artrogripose, anomalias oculares, microftalmia com cegueira e dermoide ocular bilateral. Segundo SANTOS et al. (2012), a M. tenuiflora pode representar um grande obstáculo ao desempenho reprodutivo em ovinos no semiárido, desta forma, deve-se evitar que as ovelhas tenham contato com estas plantas durante a gestação, prevenindo possíveis surtos de malformação congênita.

Palicourea marcgravii St. Hill ("Erva-de-rato" ou "Cafezinho")

Apenas $4,11 \%(N=03)$ dos produtores de ruminantes dos municípios de Cuité e Barra de Santa Rosa relataram ter conhecimentos sobre os efeitos tóxicos de $P$. marcgravii, porém não forneceram informações sobre os sinais clínicos apresentados pelos animais. Os entrevistados observaram que os animais morreram pouco tempo depois de terem se alimentado da planta.

Sabendo-se que $P$. marcgravii é uma planta de ampla distribuição geográfica, ocorrendo em praticamente todo o território brasileiro, não se sabe ao certo porque foi tão pouco mencionada pelos participantes desta pesquisa. Uma explicação plausível para este fato pode estar relacionado com o habitat desta planta, pois, segundo MAGALHÃES et al. (2013) a "Erva-de-rato" é encontrada em regiões de boa pluviosidade e terra firme, podendo ocorrer em matas secundárias, áreas de meia-sombra como capoeiras e pastos recém-formados. Enquanto que o semiárido paraibano é caracterizado por baixas médias pluviométricas e altos índices de evapotranspiração (MORAES NETO et al. 2007), o que pode se tornar um obstáculo para o estabelecimento desta planta na região.

Pesquisas indicam que $P$. marcgravii provoca intoxicações em ovinos e caprinos, podendo causar a morte destes animais. Desta forma, verifica-se que a intoxicação por $P$. marcgravii além de ser fatal, ainda é considerada de difícil diagnóstico, devido, muitas vezes, à falta de manifestações clínicas apresentadas pelos animais (SOTO-BLANCO et al. 2004). Casos de intoxicações em bovinos provocadas por esta planta foram relatados por BARBOSA et al. (2003), estes autores ressaltam que o tratamento de animais intoxicados por $P$. marcgravii não é viável, mesmo que se conhecesse um tratamento, devido à evolução superaguda da intoxicação.

Prosopis juliflora (Sw.) DC. ("Algaroba”)

Uma das plantas invasoras da Caatinga conhecida popularmente por "Algaroba" foi identificada como tóxica por $16,44 \%$ dos entrevistados dos cinco municípios estudados da microrregião do Curimataú Ocidental Paraibano.

Um engenheiro agrônomo do município de Cuité relatou que casos de intoxicações pelo consumo de vagens de "Algaroba" são muito comuns entre os bovinos. O profissional explicou que geralmente as intoxicações ocorrem quando os animais são mantidos em áreas durante os períodos de floração e frutificação da planta. Segundo RIBASKI et al. (2009), a "Algaroba" apresenta dois períodos de floração e 
frutificação, sendo o de maior intensidade na primavera, de setembro a novembro, e o outro período ocorre entre os meses de abril e junho. MEDEIROS et al. (2012) advertem que a alimentação com vagens de "Algaroba" no campo não é recomendada na alimentação de bovinos, a não ser por períodos curtos, de até 30 dias.

Dentre os principais sinais clínicos citados pelo entrevistado, destaca-se uma acentuada dificuldade para mastigar o alimento, além da "cara torta" em bovinos. GALIZA et al. (2010) destacam que alguns dos sintomas apresentados por animais intoxicados por $P$. juliflora são o desvio lateral da cabeça durante a mastigação, vulgarmente chamado de "cara torta", magreza acentuada, flacidez de mandíbula, entre outros. As vagens de $P$. juliflora, quando constituem $50 \%$ ou mais da dieta animal e são ingeridas por alguns meses causam intoxicação em bovinos e caprinos na região Nordeste do Brasil (RIET-CORREA et al. 2002). Este fato acaba sendo um assunto preocupante, tendo em vista que esta planta invasora é predominante em todo o semiárido do país.

Solanum paniculatum L. ("Jurubeba")

A S. paniculatum é uma planta tóxica amplamente encontrada na Paraíba, ocorrendo desde o litoral até a caatinga, em terrenos baldios ou abandonados e às margens de estradas, sem grande exigência quanto ao tipo de solo (AGRA et al. 2009). Porém, poucos produtores e profissionais $(4,11 \%)$ que lidam com a criação de ruminantes ressaltaram ter conhecimento sobre os princípios tóxicos da planta. Um zootecnista do município de Barra de Santa Rosa e um médico veterinário do município de Nova Floresta relataram que a planta causa alteração no comportamento dos animais, onde estes apresentam distúrbios neurológicos que ficam visíveis pela dificuldade na locomoção. GUARANA et al. (2011) evidenciaram a intoxicação natural por $S$. paniculatum em bovinos através de sinais neurológicos que se caracterizaram por crises periódicas, epileptiformes, com quedas, que surgem geralmente quando os animais são assustados ou forçados a correr.

Outras
(formulário 2).

Plantas comprovadamente tóxicas

Aspidosperma pyrifolium Mart. ("Pereiro")

Dois produtores do município de Barra de Santa Rosa afirmaram que a planta tóxica conhecida popularmente como "Pereiro" causa abortos e malformações em caprinos e ovinos, quando ingerida durante o período gestacional. Segundo os entrevistados, os animais consomem apenas a folha da planta que é muito comum na região semiárida. Há diversos relatos de intoxicação por $A$. pyrifolium em ruminantes prenhes na região Nordeste, tendo como principais sintomas aborto, parto prematuro e malformações congênitas (SILVA et al. 2006, RIET-CORREA 2007, ASSIS et al. 2010, NETO et al. 2013).

Manihot esculenta Crantz ("Mandioca")

Casos de intoxicações em ruminantes pelo consumo de folhas de "Mandioca" foram identificados por produtores dos municípios de Nova Floresta, Sossego e Damião. Um produtor do município de Damião relatou que as intoxicações são frequentes em bovinos, e que a duração da doença se desenvolve de forma rápida até a morte dos animais. Como principal medida profilática, o entrevistado ressaltou que retirou os animais do local onde havia a presença da planta para evitar novos casos de intoxicações. Em estudos realizados por SCHONS et al. (2012) também verificou-se a ocorrência de intoxicações por M. esculenta em bovinos, onde foi observado que após a ingestão deste alimento, quatro animais apresentaram dificuldade respiratória, tremores musculares e decúbito lateral. $\mathrm{O}$ autor relata que três animais conseguiram se recuperar e um morreu.

Manihot glaziovii Müll. Arg. ("Maniçoba")

No decorrer das entrevistas nos cinco municípios onde foi desenvolvida esta pesquisa, constatou-se que Manihot glaziovii tem sido uma das plantas responsáveis pela morte de ruminantes na microrregião estudada. Um produtor do município de Cuité relatou que em 2015 cinco bovinos morreram em decorrência da intoxicação por "Maniçoba". O quadro clínico dos animais se caracterizava por dificuldade para se locomover, tremores e empanzinamento. Segundo o entrevistado, foi realizado um tratamento empírico nos animais intoxicados administrando-se um xarope composto pelo extrato da própria rama de M. glaziovii, porém não existem relatos na literatura que comprovem a eficácia terapêutica do extrato de $M$. glaziovii. AMORIM et al. (2005) relatam que o tratamento aplicado nos animais intoxicados por Manihot spp. geralmente é feito utilizando uma dosagem de $50 \mathrm{ml} / 100 / \mathrm{kg} / \mathrm{pv}$ de uma solução de tiossulfato de sódio a $20 \%$, promovendo a imediata recuperação dos animais.

Em experimentos realizados por AMORIM et al. (2005), foram administradas partes da "Maniçoba" para caprinos e observou-se que os sinais clínicos eram caracterizados inicialmente por dificuldade de 
deglutição e por dispneia, seguido de mucosas cianóticas, ereção das orelhas, incoordenação, tremores musculares, nistagmo e tremor de cabeça e das pálpebras, seguidos de queda e permanência em decúbito lateral com movimentos de pedalagem e opistótono. Estes distúrbios podem estar diretamente relacionados com o efeito tóxico dos glicosídios cianogênicos (linamarina e lotaustralina) presentes na "Maniçoba" e em outras forrageiras do gênero Manihot, que quando são hidrolizados, mediante ação da enzima linamarase, resultam na produção de ácido cianídrico (HCN), que é um produto tóxico (SOUZA et al. 2010).

\section{Plantas relatadas como tóxicas, mas ainda não comprovadas cientificamente}

Physalis angulata L. ("Camapu")

A planta $P$. angulata, foi citada como tóxica para ruminantes pelos entrevistados dos municípios de Barra de Santa Rosa e Sossego. Segundo os produtores, os animais se alimentam da "rama" da planta e posteriormente desenvolvem sinais clínicos como tremores nos membros, ocorrendo a morte após algumas horas. Há pouca evidência da toxicidade de $P$. angulata. Dentre elas, o relato de 1958 na Califórnia, onde se descreveu que o gado leiteiro apresentou toxicidade a essa planta quando ingeriram feno abundante em $P$. angulata, contudo ao retirar o feno, os animais se recuperaram. Os sinais gerais observados foram perda de apetite, úberes inchados e leite aquoso (FULLER \& MCCLINTOCK 1986). A maioria dos estudos encontrados na literatura descreve atividades anti-inflamatórias, imunomoduladoras, anticancerígenas e antibacterianas (MAHALAKSHMI \& NIDAVANI 2014).

Ricinus communis L. ("Carrapadeira")

A planta Ricinus communis foi citada por quatro entrevistados do município de Barra de Santa Rosa como responsável pela morte de bovinos que se alimentaram de suas folhas verdes. Segundo um produtor, dois bovinos morreram poucas horas depois de terem ingerido partes verdes desta planta. MELLO et al. (2010) relatam que alguns produtores identificaram em seus rebanhos de bovinos, surtos de intoxicações por folhas de "Carrapateira", onde os animais apresentaram tremores e morte.

\section{CONCLUSÃO}

A partir dos resultados obtidos por meio desta pesquisa constatou-se que as principais espécies de plantas que causam intoxicações em ruminantes no Curimataú Ocidental Paraibano são: Anadenanthera colubrina (Angico); Mascagnia rigida (Tingui); Prosopis juliflora (Algaroba) e Manihot glaziovii (Maniçoba). O "Angico" e a "Maniçoba" são plantas cianogênicas e têm causado grandes perdas nas regiões onde foi realizada esta pesquisa. As mortes súbitas de bovinos, caprinos e ovinos identificadas na microrregião têm sido causadas pela ingestão do "Tingui". Foi relatado pelos entrevistados que a "Algaroba" é a principal responsável por causar uma doença em bovinos conhecida como "cara torta", muito comum nas propriedades rurais dos cinco municípios.

É importante destacar que a maioria dos produtores desconhece os efeitos tóxicos de muitas espécies de plantas amplamente difundidas nas pastagens do Curimataú Paraibano, tais como a Mimosa tenuiflora, Crotalaria retusa e a Solanum paniculatum, que causam malformações congênitas, fibrose hepática, e perturbações nervosas, respectivamente. Desta forma, conclui-se que a divulgação científica em propriedades rurais é essencial para alertar os produtores sobre as espécies de plantas tóxicas que podem ocorrer na região. Além disso, medidas profiláticas como a retirada dos animais das pastagens infestadas por plantas tóxicas, bem como o controle mecânico e a erradicação de algumas espécies de plantas invasoras, podem ser alternativas eficazes para diminuir a ocorrência de surtos e mortes dos ruminantes.

\section{REFERÊNCIAS}

AGRA MF et al. 2009. Flora da Paraíba, Brasil: Solanum L. (Solanaceae). Acta Botanica Brasilica 23: 826-842.

AMORIM SL et al. 2005. Intoxicação experimental por Manihot glaziovii (Euphorbiaceae) em caprinos. Pesquisa Veterinária Brasileira 25: 179-187.

AMOROZO MCM \& GÉLY A. 1988. Uso de plantas medicinais por cablocos do baixo Amazonas Barcarena, PA, Brasil. Boletim do Museu Paraense Emílio Goeldi 4: 47-131.

ARAÚJO LVC et al. 2004. Estimativa da produção de biomassa de um povoamento de jurema-preta (Mimosa tenuiflora (Willd.) Poiret. com cinco anos de idade. Biomassa \& Energia 1: 347-352.

ARAÚJO JAS et al. 2008. Intoxicação experimental por Ipomoea asarifolia (Convolvulaceae) em caprinos e ovinos. Pesquisa Veterinária Brasileira 28: 488-494.

ARAÚJO MM. 2009. Estudo etnobotânico das plantas utilizadas como medicinais no assentamento Santo Antônio, Cajazeiras. Dissertação (Mestrado em Ciências Florestais e Ambientais). Patos: UFCG. 130p.

ASSIS TS et al. 2010. Intoxicações por plantas diagnosticadas em ruminantes e equinos e estimativa das perdas econômicas na Paraíba. Pesquisa Veterinária Brasileira 30: 13-20.

BARBOSA JD et al. 2003. Comparação da sensibilidade de bovinos e búfalos à intoxicação por Palicourea marcgravii (Rubiaceae). Pesquisa Veterinária Brasileira 23: 167-172.

Rev. Ciênc. Agrovet., Lages, SC, Brasil (ISSN 2238-1171) 
BARBOSA JD et al. 2005. Intoxicações experimental e natural por Ipomoea asarifolia (Convolvulaceae) em búfalos e outros ruminantes. Pesquisa Veterinária Brasileira 25: 231-234.

BARBOSA RR et al. 2007. Plantas tóxicas de interesse pecuário: importância e formas de estudo. Acta Veterinaria Brasilica 1: 1-7.

BEZERRA CWC et al. 2012. Plantas tóxicas para ruminantes e equídeos da microrregião do Cariri Cearense. Ciência Rural 42: 1070-1076.

BRITO MF et al. 2004. A toxidez de diversas lantanas para bovinos e ovinos no Brasil. Pesquisa Veterinária Brasileira 24: 153-159.

CARVALHO GD et al. 2009. Principais plantas tóxicas causadoras de morte súbita em bovinos no estado do Espírito Santo-Brasil. Archivos de Zootecnia 58: 87-98.

COSTA RG et al. 2007. Caracterização dos rebanhos caprinos e ovinos na região semi-árida do estado da Paraíba. Revista Científica de Produção Animal 9: 127-136.

COSTA RLD et al. 2009. Um caso de intoxicação de bovinos por Enterolobium contortisiliquum (Timboril) no Brasil. Archivos de Zootecnia 58: 313-316.

DANTAS AFM et al. 2010. Malformações congênitas em ruminantes no semiárido do Nordeste Brasileiro. Pesquisa Veterinária Brasileira 30: 807-815.

FULLER TC \& MCCLINTOCK EM. 1986. Poisonous Plants of California. Berkeley: University of California Press. 433p.

FIEP/SEBRAE. 2010. Federação das Indústrias do Estado da Paraíba/Serviço Brasileiro de Apoio às Micros e Pequenas Empresas. Campina Grande: FIEP/PB.

GALIZA GJN et al. 2010. Doenças do sistema nervoso de bovinos no semiárido nordestino. Pesquisa Veterinária Brasileira 30: 267-276.

GUARANA ELS et al. 2011. Intoxicação por Solanum paniculatum (Solanaceae) em bovinos. Pesquisa Veterinária Brasileira 31: 59-64.

IBGE. 2006. Instituto Brasileiro de Geografia e Estatística. CENSO 2006. Disponível em: <http://www.sidra.ibge.gov.br> Acesso em: 15 dez. 2016.

IBGE. 2010. Instituto Brasileiro de Geografia e Estatística. CENSO 2010. Disponível em: <http://www.sidra.ibge.gov.br>. Acesso em: 15 dez. 2016.

LUCENA RB et al. 2010. Intoxicação por alcaloides pirrolizidínicos em ruminantes e equinos no Brasil. Pesquisa Veterinária Brasileira 30: 447-452.

MAHALAKSHMI AM \& NIDAVANI RB. 2014. Physalis angulata L.: An ethanopharmacological review. Indo American Journal of Pharmaceutical Research 4: 1479-1486.

MAGALHÃES RMF et al. 2013. Plantas tóxicas de interesse pecuário encontradas na região nordeste do Brasil: Uma Revisão. Revista Brasileira de Higiene e Sanidade Animal 7: 79-102.

MEDEIROS MA et al. 2012. Utilização de vagens de Prosopis juliflora na alimentação de bovinos e equinos. Pesquisa Veterinária Brasileira 32: 1014-1016.

MELLO GWS et al. 2010. Plantas tóxicas para ruminantes e eqüídeos no Norte Piauiense. Pesquisa Veterinária Brasileira 30: 1-9.

MORAES NETO JM et al. 2007. Efeito dos eventos ENOS e das TSM na variação pluviométrica do semi-árido paraibano. Revista Brasileira de Engenharia Agrícola Ambiental 11: 61-66.

NETO SAG et al. 2013. Inquérito epidemiológico sobre plantas tóxicas das mesoregiões Central e Oeste do Rio Grande do Norte. Ciência Rural 43: 1281-1287.

NOBRE VMT et al. 2005. Acute intoxication by Crotalaria retusa in sheep. Toxicon 45: 347-352.

OLINDA RG et al. 2015. Intoxicação por Enterolobium contortisiliquum em bovinos na região Nordeste do Brasil. Pesquisa Veterinária Brasileira 35: 44-48.

OLIVEIRA CA et al. 2009. Intoxicação por Ipomoea carnea subsp. Fistulosa (Convolvulaceae) em caprinos na Ilha do Marajó, Pará. Pesquisa Veterinária Brasileira 29: 583-588.

PESSOA CRM et al. 2013. Importância econômica, epidemiologia e controle das intoxicações por plantas no Brasil. Pesquisa Veterinária Brasileira 33: 752-758.

PESSOA DAN et al. 2015. Resistência à intoxicação por Amorimia septentrionalis em caprinos, induzida pela inoculação ruminal das bactérias Pigmentiphaga kullae e Ancylobacter dichloromethanicus. Pesquisa Veterinária Brasileira 35:125-128.

RIBASKI J et al. 2009. Algaroba (Prosopis juliflora): árvore de uso múltiplo para a região semiárida brasileira. Embrapa Florestas: INFOTECA-E. 8p. (Comunicado Técnico 240).

RIET-CORREA F et al. 2002. Importância do exame clínico para o diagnóstico das enfermidades do sistema nervoso em ruminantes e eqüídeos. Pesquisa Veterinária Brasileira 22: 161-168.

RIET-CORREA F. 2007. Plantas tóxicas e micotoxinas que afetam a reprodução em ruminantes e eqüinos no Brasil. Biológico 69: 63-68.

RIET-CORREA B et al. 2011. Intoxicação por Brachiaria spp. em ruminantes no Brasil. Pesquisa Veterinária Brasileira 31: 183-192.

RIET-CORREA F et al. 2012. A pecuária brasileira e as plantas tóxicas. Revista UFG 13: 83-91.

SANTOS JCA et al. 2008. Patogênese, sinais clínicos e patologia das doenças causadas por plantas hepatotóxicas em ruminantes e eqüinos no Brasil. Pesquisa Veterinária Brasileira 28: 1-14.

SANTOS JRS et al. 2012. Malformações, abortos e mortalidade embrionária em ovinos causada pela ingestão de

Rev. Ciênc. Agrovet., Lages, SC, Brasil (ISSN 2238-1171) 210 
Mimosa tenuiflora (Leguminosae). Pesquisa Veterinária Brasileira 32: 1103-1106.

SCHONS SV et al. 2012. Intoxicações por plantas em ruminantes e equídeos na região central de Rondônia. Ciência Rural 42: 1257-1263.

SILVA DM et al. 2006. Plantas tóxicas para ruminantes e eqüídeos no Seridó Ocidental e Oriental do Rio Grande do Norte. Pesquisa Veterinária Brasileira 26: 223-236.

SILVA IP et al. 2008. Intoxicação natural pelas folhas de Mascagnia rigida (Malpighiaceae) em ovinos. Arquivos do Instituto Biológico 75: 229-233.

SOTO-BLANCO B et al. 2004. Intoxicação natural de caprinos e ovinos por Palicourea marcgravii St. Hill. (Rubiaceae). Caatinga 17: 52-56.

SOUZA EJO de et al. 2010. Comportamento ingestivo e ingestão de água em caprinos e ovinos alimentados com feno e silagem de Maniçoba. Revista Brasileira de Saúde e Produção Animal 11: 1056-1067.

SOUZA RIC et al. 2010. Intoxicação por Brachiaria spp. em bovinos no Mato Grosso do Sul. Pesquisa Veterinária Brasileira 30: 1036-1042.

TORTELLI FP et al. 2008. Intoxicação por Ipomoea asarifolia em ovinos e bovinos na llha de Marajó. Pesquisa Veterinária Brasileira 28: 622-626.

TOKARNIA CH et al. 1999a. Estudos complementares sobre a toxidez de Lantana camara (Verbenaceae) em bovinos. Pesquisa Veterinária Brasileira 19: 128-132.

TOKARNIA CH et al. 1999b. Experimentos em bovinos com as favas de Enterolobium contortisiliquum e E. timbouva para verificar propriedades fotossensibilizantes e/ou abortivas. Pesquisa Veterinária Brasileira 19: 39-45.

TOKARNIA CH et al. 1999c. Estudos experimentais com plantas cianogênicas em bovinos. Pesquisa Veterinária Brasileira 19: 84-90.

VASCONCELOS JS et al. 2008. Intoxicação por Mascagnia rigida (Malpighiaceae) em ovinos e caprinos. Pesquisa Veterinária Brasileira 28: 521-526. 